\title{
Dynamic Amplification of an Orthotropic, Multi Span Bridge Deck under Moving Truck with Tandem Axles
}

\author{
Youcef Fisli ${ }^{1}$, Abdelouahab Rezaiguia ${ }^{1}$, Salah Guenfoud ${ }^{1}$, \\ Debra F. Laefer ${ }^{2}$, and Mounia Kaddeche ${ }^{1}$ \\ ${ }^{1}$ Applied Mechanics of New Materials Laboratory, Guelma University, \\ P.O.B 401, Guelma 24000, Algeria \\ ${ }^{2}$ Urban Modeling Group, School of Civil, Structural and Environmental Engineering, \\ University College Belfield, Dublin 4, Ireland \\ debra.laefer@ucd.ie
}

\begin{abstract}
Vehicles crossing bridges at high speeds can cause significant dynamic effects and must be studied by accurately simulating the interactive, dynamic responses of the bridge deck and the load-applying vehicles. Specifically, a multispan, orthotropic, bridge deck during truck loading is investigated to better understand the dynamic interaction between moving vehicles with tandem axles and highway bridge decks. The vehicle is modeled by a three-dimensional dynamic system with tandem axles with 9 degrees of freedom. The bridge deck is modeled by a thin, orthotropic, multi-span plate. The road surface irregularities are modeled by a random function characterized by a spectral roughness coefficient and power spectral density. The modal method is used to solve the equation of motion of the bridge deck. Equations of motion of the vehicle are obtained using a virtual work principle. The coupled equations of motion vehicle/bridge deck are integrated numerically by Newmark's method. A computational algorithm in FORTRAN is used to solve the integrated equations of motion in a decoupled, iterative process. A numerical example of an orthotropic, three-span bridge deck, excited in nine degrees of freedom truck is presented. The resulting distribution of the Dynamic Amplification Factor on the bridge deck does not reflect any particular trend, because high values of the DAF can be obtained at points where the vertical displacement is small. The DAF is significant only under the interaction force. Thus, the road surface roughness had a significant influence on the dynamic vehicle/bridge deck interaction forces.
\end{abstract}

Keywords: dynamic interaction, orthotropic bridge deck, vehicle, tandem axles. 


\section{Introduction}

The difference in a structure's response under dynamic loading versus static loading is described as its Dynamic Amplification Factor (DAF) and is an especially important phenomenon in the design and analysis of bridges. The DAF caused by vehicles depends on several factors: pavement roughness and singular periodic irregularities of the surface, irregularities of the wheels directly, each vehicle's mass, and speed, as well as the stiffness and damping of the suspension system of the vehicle. The dynamic response of a bridge depends on span lengths, the natural frequencies of vibration, support types, soil-structure interaction, the physical condition of the bridge, and the viscous damping, etc, (Isabel 2001).

To investigate these issues Zhu and Law (2002) modeled the deck of a multispan highway bridge by a rectangular orthotropic plate with rigid, intermediate supports. Their vehicle was modeled with a three-dimensional dynamic system with seven degrees of freedom. They studied the influence of the position of the vehicle track on the dynamic response of the bridge and the influence of running speed and road surface irregularities on the dynamic amplification factor of the bridge. In related work Yang et al. (2004) studied the extraction of fundamental frequencies of a bridge from the dynamic response due to the passage of the vehicle; the objective was to comprehend the influence of the vehicle speed on the frequencies of the bridge. They showed in both analytical and finite-element studies that the bridge frequency can be extracted from the vehicle acceleration spectrum. Subsequently, Cai et al. (2007) developed a fully automatic coupled vehicle/bridge model. The methodology was validated with practical experiments on a typical bridge. The results of the experiments showed that this coupled model reliably predicted the dynamic response of bridges by taking into account the roadway irregularities and concluded that the initial conditions of the incoming vehicles on the bridge have a significant influence.

Since then, Yin et al. (2010) presented a method to analyze the non-stationary random response of bridges using the equivalence of a covariance technique. In that, they employed a model of the vehicle with two axles and analyzed three typical bridge models. Numerical results indicated that the non-stationary, random response amplitude of wheels is proportional to the vehicle speed. They also showed that employing a stationary process to model the disturbance of the roadway profile at different speeds can both underestimate and overestimate the dynamic effects. In related work, Rezaiguia (2008) studied the vibro-acoustic behavior of a multi-span, highway bridge during the passage of vehicle. As part of this, the inclusion of the bridge-vehicle dynamic interaction and random irregularities of the track pavement were investigated.

In this context, this paper investigates the dynamic behavior of a multi-span bridge deck during a passing truck and taking into account the dynamic interaction truck-bridge and random irregularities of the highway profile. The bridge deck is modeled as an orthotropic three-span plate. The truck is modeled dynamically with nine degrees of freedom and tandem axles at the rear. The road surface 
roughness is modeled by a random function characterized by a power spectral density and spectral roughness coefficient. The modal approach coupled with a numerical integration by Newmark method is used to solve the coupled equations of bridge-truck motion because it is an unconditionally stable direct method of maximum precision. Solving these equations was achieved in an uncoupled manner using iterative calculations.

\section{$2 \quad$ Modeling}

\subsection{Vehicle Model}

The vehicle is modeled with a dynamic, lumped-mass system. The threedimensional (3D), three-axle vehicle with a tandem axle has 9 degrees of freedom and consists of a rigid block supported by 6 wheels, as shown in Fig.1. The rigid body representing the truck chassis has three degrees of freedom $\left(z_{v 1}, z_{v 2}, z_{v 3}\right)$ to describe the displacements and rotations of the chassis. The masses of the axles and wheels are concentrated in lumped masses $\left(m_{1}\right.$ to $\left.m_{6}\right)$ within the suspension system, leading to a further six degrees of freedom $\left(z_{1}, z_{2}, z_{3}, z_{4}, z_{5}, z_{6}\right)$ to describe the vertical wheel displacements. The tire stiffness is modeled using linear springs and viscous dampers.

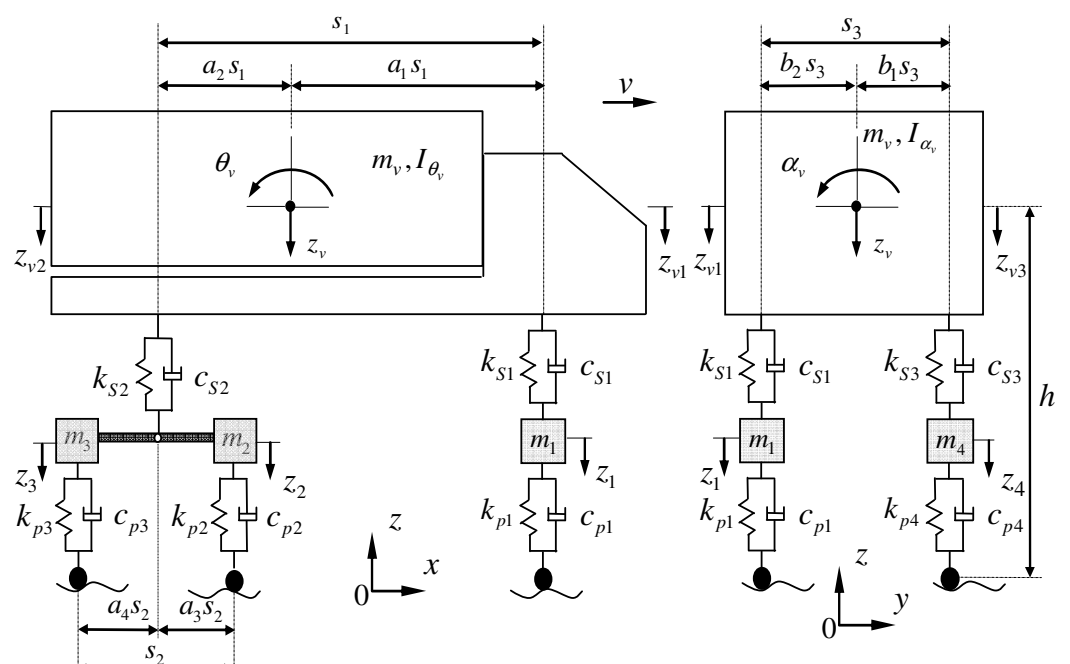

(a)

(b)

Fig. 1 Three-axle vehicle model with 9 degrees of freedom, (a): side view, (b): front view 
In Fig. $1, m_{i}, i=1,2, \ldots, 6$ are the masses of the wheels with axles of the front and rear axles, $m_{v}, I_{\theta v}$ and $I_{\alpha \nu}$ are the mass and moments of inertia of rigid block of the truck, $k_{p i}, i=1,2, \ldots, 6$ and $c_{p i}, i=1,2, \ldots, 6$ are the tire rigidities and damping respectively, $k_{s i}, i=1,2, \ldots, 4$ and $c_{s i}, i=1,2, \ldots, 4$ are the suspension rigidities and damping, respectively.

The equations of motion of the vehicle model are obtained by applying the virtual work principle. The vertical displacements of the vehicle model are calculated from its static, equilibrium position. In Fig.2, the forces and moments acting on the vehicle are presented. The equation of virtual work for any virtual vehicle displacement can be expressed in matrix form as:

$$
\left[M_{v}\right]\left\{\ddot{Z}_{v}\right\}+\left[C_{v}\right]\left\{\dot{Z}_{v}\right\}+\left[K_{v}\right]\left\{Z_{v}\right\}=\left\{F_{g}\right\}+\left\{F^{\text {int }}\right\}
$$

Where $\left\{F^{\text {int }}\right\}$ is the interaction force vector applied to the vehicle, $\left\{F_{g}\right\}$ is the force vector caused by the effect of gravity; $\left[M_{v}\right],\left[C_{v}\right]$ and $\left[K_{v}\right]$ are, respectively, the mass, damping, and stiffness matrices of the vehicle, and $\left\{Z_{v}\right\}$ is the vertical displacement vector of the vehicle's degrees of freedom.

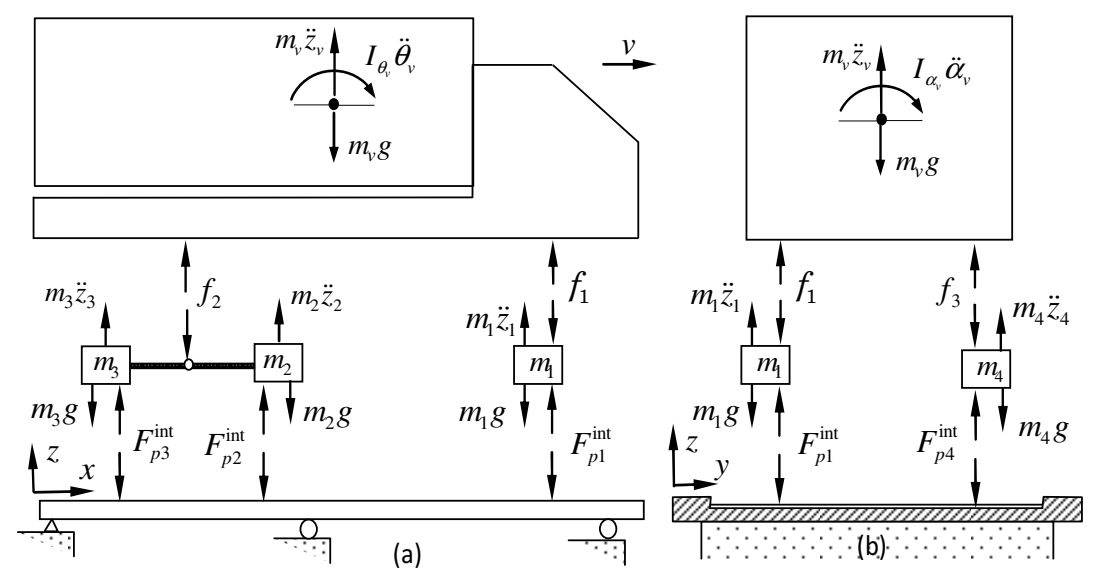

Fig. 2 Dynamic equilibrium of forces and moments, (a): side view, (b): front view

\subsection{Bridge Deck Model}

The bridge deck is modeled as a multi-span, orthotropic, rectangular plate. The bridge is continuous on the supports, simply supported in $x=0$ and $x=l$ and free in $y=0$ and $y=b$ (Fig. 3). The bridge has a linear elastic behavior, and the secondary effects (shearing and inertia of rotation) are neglected. The intermediate supports are linearly rigid and orthogonal at the free edges of the 
bridge. As the dimensions (length and width) of the bridge deck are much larger compared to its thickness, the thin plate theory is used. The equation of motion of the bridge deck can be written as follows:

$$
\bar{m} \frac{\partial^{2} w}{\partial t^{2}}+c \frac{\partial w}{\partial t}+D_{x} \frac{\partial^{4} w}{\partial x^{4}}+2 H \frac{\partial^{4} w}{\partial x^{2} \partial y^{2}}+D_{y} \frac{\partial^{4} w}{\partial y^{4}}=-\sum_{k=1}^{n f} F_{p k}^{\mathrm{int}} \delta\left(x-x_{k}(t), y-y_{k}\right)
$$

where $\bar{m}=\rho h$ is the mass density of the plate; $c$ is the viscous damping coefficient of the bridge deck; $D_{x}=E_{x} h^{3} / 12\left(1-v_{x y} v_{y x}\right)$ and $D_{y}=E_{y} h^{3} / 12\left(1-v_{x y} v_{y x}\right)$ are flexural rigidities according to $x$ - and y-directions, respectively; $H=v_{x y} D_{y}+2 D_{x y}$ is the equivalent flexural rigidity; $v_{x y}$ and $v_{y x}$ are the Poisson's ratios according to $x$ - and $y$-directions respectively; $D_{x y}=G_{x y} h^{3} / 12$ is the torsional rigidity of the bridge deck; $G_{x y}$ is the shear modulus for the $x$-y plane, $E_{x}$ and $E_{y}$ are the Young's moduli according $x$-and $y$ directions respectively; $F_{p k}^{\text {int }}$ is the interaction force between the $k^{\text {th }}$ wheel of the vehicle and the bridge, $\left(x_{k}(t), y_{k}(t)\right)$ is the position of the $k^{\text {th }}$ interaction force on the bridge.

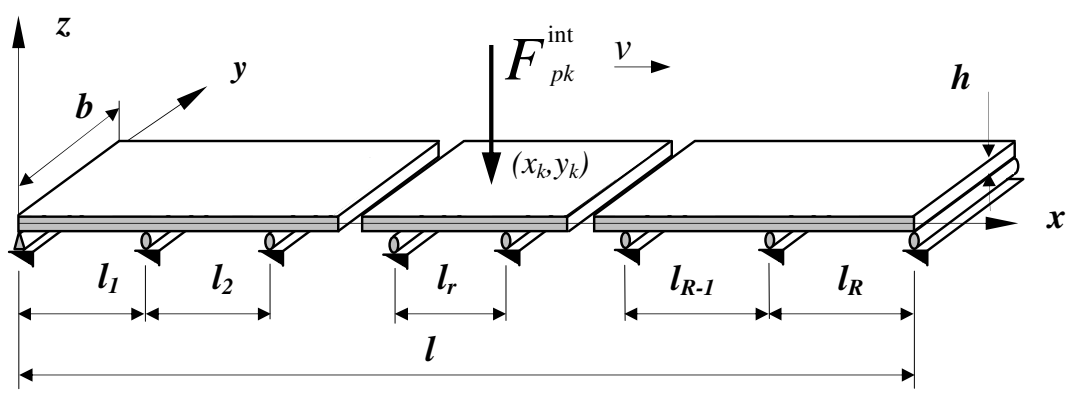

Fig. 3 Model of the continuous multi-span bridge deck

Appling the modal superposition method to the bridge deck, the vertical displacement of the orthotropic plate can be written as follows:

$$
w(x, y, t)=\sum_{i=1}^{n} \sum_{j=1}^{m} \phi_{i j}(x, y) q_{i j}(t)
$$

where $\phi_{i j}(x, y)$ are the mode shapes of a multi-span, continuous, orthotropic plate (Rezaiguia and al 2012), and $q_{i j}(t)$ are the generalized coordinates. 
Substituting equation (3) into equation (2), multiplying by $\phi_{k l}(x, y)$, integrating over the bridge deck surface, and applying the orthogonality conditions of mode shapes, the modal decoupled equations of the system are obtained, as shown in eq. (4).

$$
M_{i j} \ddot{q}_{i j}+C_{i j} \dot{q}_{i j}+K_{i j} q_{i j}=F_{i j}
$$

where $M_{i j}, C_{i j}$ and $K_{i j}$ are the modal mass, modal damping, and modal stiffness of the bridge deck, respectively, and $F_{i j}$ are the modal interaction forces.

\subsection{Road Surface Roughness}

The road surface roughness is modeled by a random function as per equation 5 .

$$
r\left(x_{k}\right)=\sum_{i=1}^{N} \sqrt{4 A_{r}\left(\frac{2 \pi i}{L_{c} \omega_{s 0}}\right)^{-2} \frac{2 \pi}{L_{c}}} \cos \left(\omega_{s i} x_{k}+\theta_{i}\right), k=1, \ldots, 6
$$

where $A_{r}$ is the spectral roughness coefficient ( $\mathrm{m}^{3} /$ cycle) whose value is chosen depending on the road condition, $\omega_{s 0}$ is the discontinuity pulsation $\left(\omega_{s 0}=1 / 2 \pi\right.$ cycle $/ \mathrm{m}), \omega_{s i}$ is the wave number $\left(\omega_{s i}=2 \pi i / L_{c}\right.$ cycle $\left./ \mathrm{m}\right)$. Generally $L_{c}$ is equal to $2 l$ (m), where $l$ is the length of the bridge $(\mathrm{m}) . N$ is the number of descritization points in wave number domain; and $\theta_{i}$ is a random variable that varies between 0 and $2 \pi$.

\subsection{Vehicle-Bridge Deck Interaction Forces}

The interaction force between the bridge and $i$ th vehicle wheel is given by:

$$
\begin{aligned}
F_{p k}^{\mathrm{int}}=k_{p k}\left[z_{k}-w\left(x_{k}, y_{k}, t\right)-r\left(x_{k}, y_{k}\right)\right] \\
+c_{p k}\left[\dot{z}_{k}-\frac{\partial w}{\partial t}\left(x_{k}, y_{k}, t\right)-\left(\frac{\partial w}{\partial x}+\frac{\partial r}{\partial x}\right)_{x=x_{k}, y=y_{k}} \dot{x}_{k}\right] k=1, \ldots, 6
\end{aligned}
$$

where $w\left(x_{i}(t), y_{i}(t), t\right)$ is the vertical bridge displacement under the $i$ th wheel, $r\left(x_{i}(t), y_{i}(t)\right)$ is the road surface roughness under the $i$ th wheel, and $z_{i}$ is the vertical displacement of the $i$ th wheel.

\section{Solving Equations of Motion}

To solve the coupled equations of motion of the bridge deck and the vehicle, Newmark's numerical integration method was applied. To achieve this, an 
algorithm was developed for solving coupled equations of motion in a decoupled manner and an iterative calculation process.

\section{Numerical Example}

In this example, the dynamic behavior of a deck slab bridge is modeled by a threespan orthotropic rectangular plate was excited with a moving vehicle modeled by a dynamic model with nine degrees of freedom. The equivalent properties of the deck slab are as per Rezaiguia (2008): $l=78 \mathrm{~m}, l_{1}=l_{3}=24 \mathrm{~m}$ and $l_{2}=30 \mathrm{~m}, \mathrm{~b}=$ $13.715 m, h=0.212 m, \rho=3265 \mathrm{kgm}^{-3}, D_{x}=2.41 \times 10^{9} \mathrm{Nm}, D_{y}=2.18 \times 10^{7} \mathrm{Nm}$, $D_{x y}=1.14 \times 10^{8} \mathrm{Nm}, v_{x y}=0.3, E_{x}=3.06 \times 10^{12} \mathrm{~N} / \mathrm{m}^{2}, E_{y}=2.76 \times 10^{10} \mathrm{~N} / \mathrm{m}^{2}, G_{x y}=$ $1.45 \times 10^{11} \mathrm{~N} / \mathrm{m}^{2}$. The natural frequencies and mode shapes of three-span orthotropic bridge deck were calculated with recently developed approach based on the modal method taking into account the effect of intermodal coupling neglected in previous similar studies. The first ten natural frequencies of the deck slab were as reported in Rezaiguia and Laefer (2009): 4.13, 5.45, 6.30, 7.59, 7.75, 9.77, 9.08, 11.26, 11.97, and 15.07. The vehicle model parameters were assigned as per Broquet (1999): $m_{v}=248000 \mathrm{~kg}, m_{1}=m_{4}=800 \mathrm{~kg}, m_{2}=m_{5}=1200 \mathrm{~kg}, m_{3}=$ $m_{6}=1200 \mathrm{~kg}, I_{\theta v}=241359 \mathrm{kgm}^{2}, I_{\alpha v}=34878.46 \mathrm{kgm}^{2}, \mathrm{~h}=1.8 \mathrm{~m}, S_{1}=5.55 \mathrm{~m}$, $S_{2}=1.8 \mathrm{~m}, a_{1}=0.71, a_{2}=0.29, a_{3}=a_{4}=0.5, b_{1}=b_{2}=0.5, k_{s 1}=k_{s 3}=520000 \mathrm{~N} / \mathrm{m}$, $k_{s 2}=k_{s 4}=2348000 \mathrm{~N} / \mathrm{m}, k_{p 1}=k_{p 4}=2000000 \mathrm{~N} / \mathrm{m}, k_{p 2}=k_{p 3}=k_{p 5}=k_{p 6}=4000000$ $\mathrm{N} / \mathrm{m}, c_{s 1}=c_{s 3}=12194 \mathrm{Ns} / \mathrm{m}, c_{s 2}=c_{s 4}=40715 \mathrm{Ns} / \mathrm{m}, c_{p 1}=c_{p 4}=4000 \mathrm{Ns} / \mathrm{m}, c_{p 2}=c_{p 3}$ $=c_{p 5}=c_{p 6}=6928 \mathrm{Ns} / \mathrm{m}$.

\subsection{Influence of the Loading Mode}

Several numerical simulations were performed to identify the influence of the moving load on the dynamic responses of the deck slab bridge. The truck traversed the bridge at a speed of $100 \mathrm{~km} / \mathrm{h}$ along three different paths (Fig. 4).

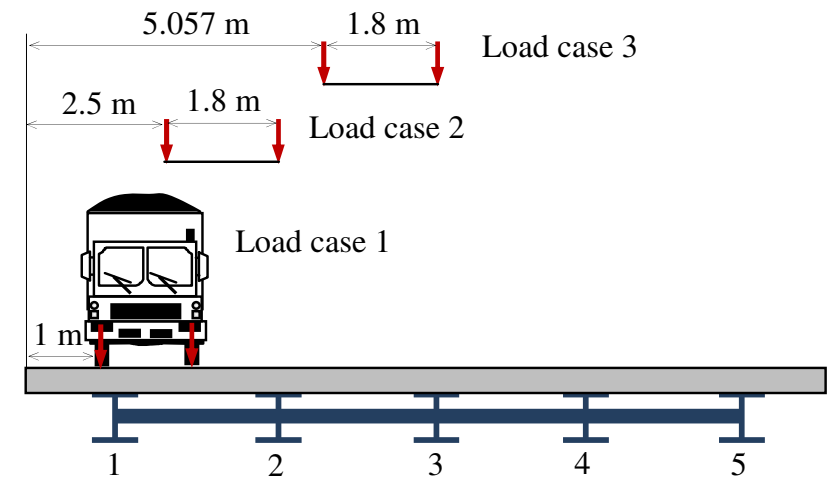

Fig. 4 Vehicle loading 
Table 1 shows the influence of the loading mode on the DAF calculated in the middle of each span and in the middle of each girder. The maximum static response is obtained with the truck moving at the very slow speed of $0.01 \mathrm{~m} / \mathrm{s}$. Based on those conditions, the following was observed

- The DAF is small near the vehicle and higher further away.

- The DAF of the middle of girders 4 and 5 were the highest for the first and second loading cases $(\mathrm{DAF}=2.63$ and 2.19). This may be due either to torsional modes excited by these loading cases or with the definition itself of the dynamic amplification factor as a response indicator.

Table 1 Distribution of the dynamic amplification factor on the bridge deck

\begin{tabular}{ccccccc}
\hline \multirow{2}{*}{ Load case } & \multirow{2}{*}{ Span } & \multicolumn{5}{c}{ Dynamic Amplification Factor } \\
\cline { 3 - 7 } & 1 & Girder 1 & Girder 2 & Girder 3 & Girder 4 & Girder 5 \\
\hline \multirow{2}{*}{1} & 2 & 1.337 & 1.371 & 1.501 & 1.889 & $\mathbf{2 . 6 3 0}$ \\
& 3 & 1.072 & 1.089 & 1.153 & 1.288 & 1.723 \\
& 1 & 1.333 & 1.157 & 1.194 & 1.291 & 1.778 \\
2 & 2 & 1.072 & 1.360 & 1.435 & 1.695 & $\mathbf{2 . 1 9 1}$ \\
& 3 & 1.137 & 1.135 & 1.171 & 1.224 & 1.402 \\
& 1 & 1.465 & 1.383 & 1.377 & 1.456 & 1.636 \\
3 & 2 & 1.108 & 1.082 & 1.081 & 1.104 & 1.171 \\
& 3 & 1.154 & 1.138 & 1.128 & 1.168 & 1.184 \\
\hline
\end{tabular}

Fig. 5 illustrates the influence of the loading mode on the vertical displacement at the middle point of a three-span bridge deck. This image shows the following

- High vertical displacement near the applied load, while the DAF is the opposite (see Table 1 and Fig.5).

- Positive vertical displacement when the load is eccentric (i.e. when the truck is located on either the first or the third span).

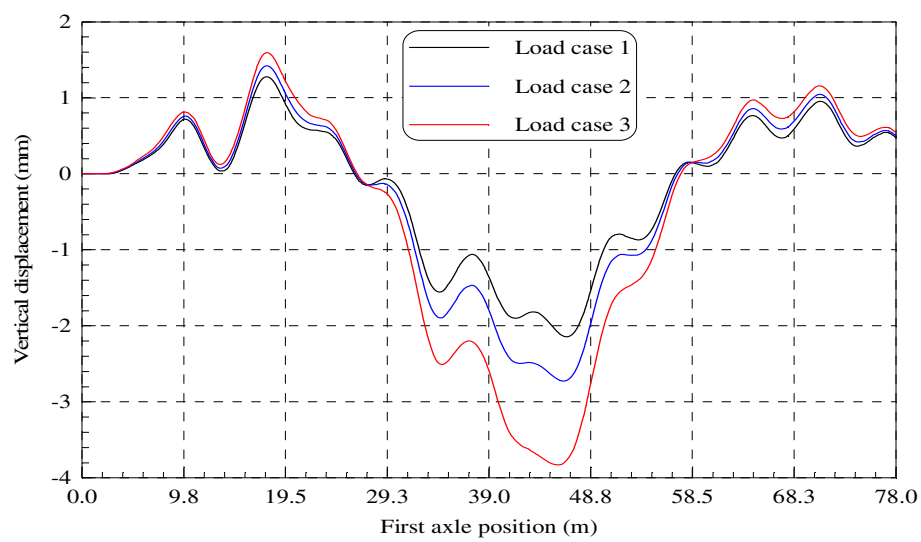

Fig. 5 Vertical displacement at middle of span 2 of girder 3 under different loading 


\subsection{Influence of Vehicle Speed}

Figures 6 show the variation of the dynamic amplification factor of the bridge deck at the middle point girder 1 and 3 and in the middle of the span 2 under different loading cases as a function of the vehicle speed selected between 10 and $160 \mathrm{~km} / \mathrm{h}$. the DAF varies little up to vehicle speeds of around $110 \mathrm{~km} / \mathrm{h}$ after which a rapid increase occurs to a critical speed of $133.2 \mathrm{~km} / \mathrm{h}$ followed by a rapid decline.
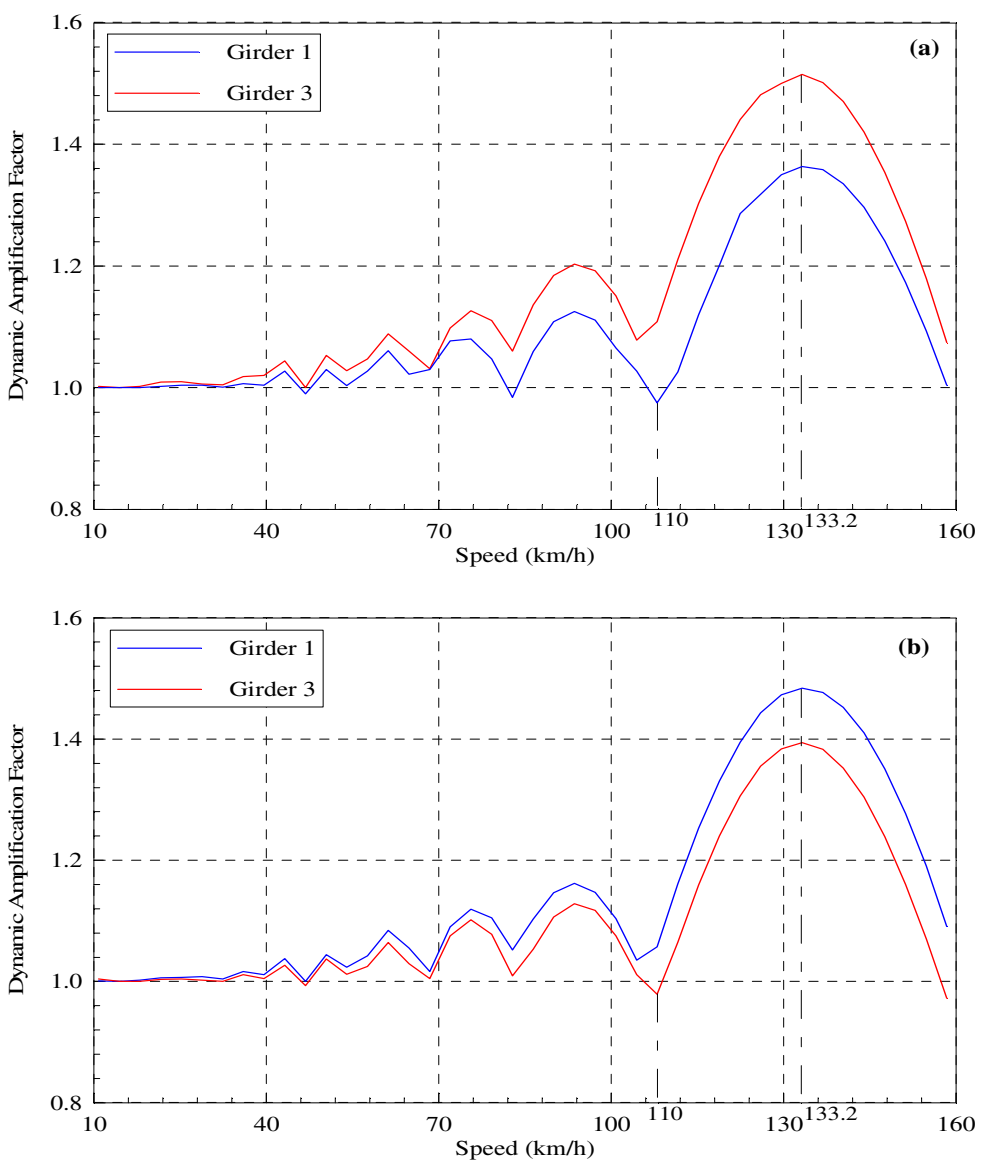

Fig. 6 Dynamic amplification factor at middle of span 2 of girder 1 and girder 3 as function of vehicle speed, (a): load case 1, (b): load case 3 


\subsection{Influence of Vehicle Mass}

The mass difference between the loaded and unloaded truck can cause changes in the dynamic behavior of the bridge deck. To identify the influence of the truck mass on the dynamic response of the bridge deck, three load levels were simulated for the truck used: an unloaded truck $\left(m_{v}=8200 \mathrm{~kg}\right)$, a normally loaded truck $\left(m_{v}=24800 \mathrm{~kg}\right)$, and an overloaded truck $\left(m_{v}=31300 \mathrm{~kg}\right)$. Fig.7 shows the influence of the vehicle mass on the vertical displacement in the middle of the bridge deck. The truck through the bridge according to path of the load case 3 at a speed of $80 \mathrm{~km} / \mathrm{h}$. As expected, there is an increase of the vertical displacement in the middle of the bridge deck, especially when the truck is overloaded and located in the central span.

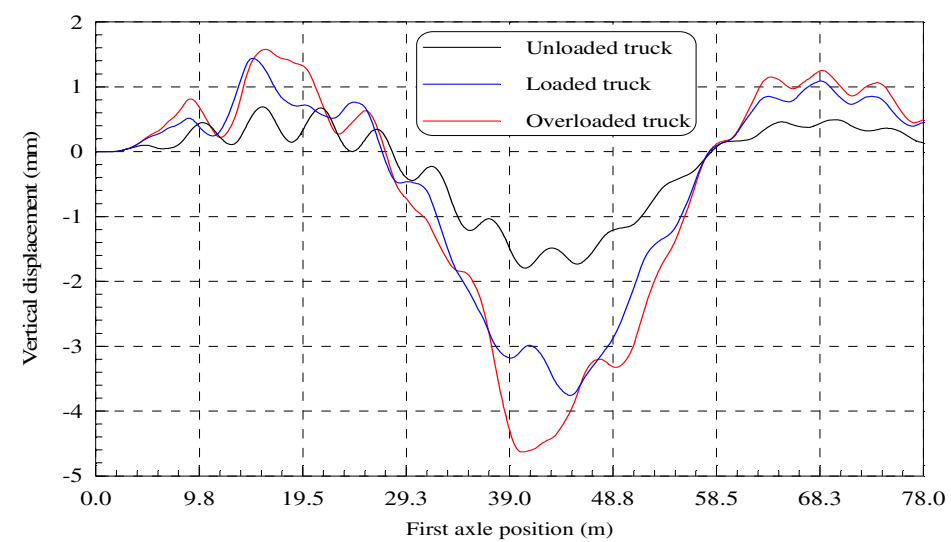

Fig. 7 Vertical displacement at middle of span 2 of girder 3 under different mass vehicle, $v_{x}$ $=80 \mathrm{~km} / \mathrm{h}$, load case 3

Fig. 8 shows the influence of the truck mass on the dynamic amplification factor in the middle of girder 3 and the middle of span 2 with truck speeds from 10 to $160 \mathrm{~km} / \mathrm{h}$. Those results demonstrated the following:

- The critical speed corresponding to the maximum dynamic amplification factor decreases with the truck mass: for the unloaded truck, the critical speed was $144 \mathrm{~km} / \mathrm{h}$, for the normally loaded truck, the critical speed was $133.2 \mathrm{k} / \mathrm{h}$, and for the overloaded truck, the critical speed was $126 \mathrm{~km} / \mathrm{h}$.

- For the critical speed, the DAF was higher in case of the normally loaded truck. 


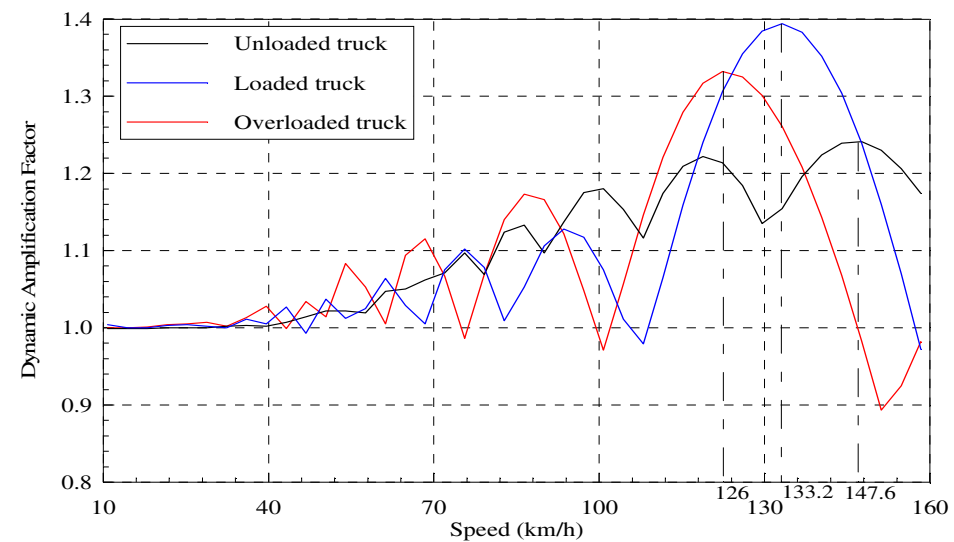

Fig. 8 Influence of vehicle mass on dynamic amplification factors in the middle of the bridge deck

\subsection{Influence of Road Surface Roughness}

Figure 9 shows the influence of the road surface roughness on the dynamic amplification factor in the middle of span 2, girder 3, for vehicle speeds varying from 10 to $160 \mathrm{~km} / \mathrm{h}$. The vehicle passes along the bridge deck under loading case 3. Notably, increased road surface roughness increases the DAF in the tread slab. Additionally at a speed of $133.2 \mathrm{~km} / \mathrm{h}$ and a bad road surface $\left(A_{r}=\right.$ $150 \times 10^{-6} \mathrm{~m}^{3} /$ cycle), an increase of about $25 \%$ of the maximum value of the DAF occurred.

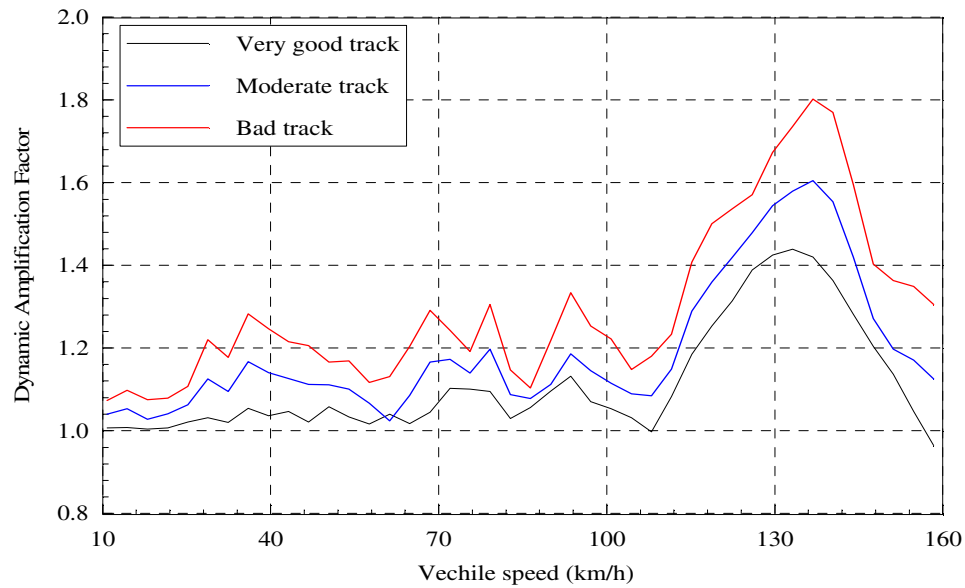

Fig. 9 Influence of the state of the track on the dynamic amplification factor in the middle of the deck slab for loading case 3 
Figure 10 shows the variation of the interaction forces exerted by a right rear wheel of the vehicle based on the track condition. The vehicle was moving at a speed of $100 \mathrm{~km} / \mathrm{h}$ according to load case 3 .The results showed that changes in the amplitudes of the interaction forces increased significantly with greater track profile roughness. This means that the state of the track can significantly influence the vehicle vibrations than the rolling slab. Additionally, the interaction forces fluctuated around an average value, which corresponded to the static force.

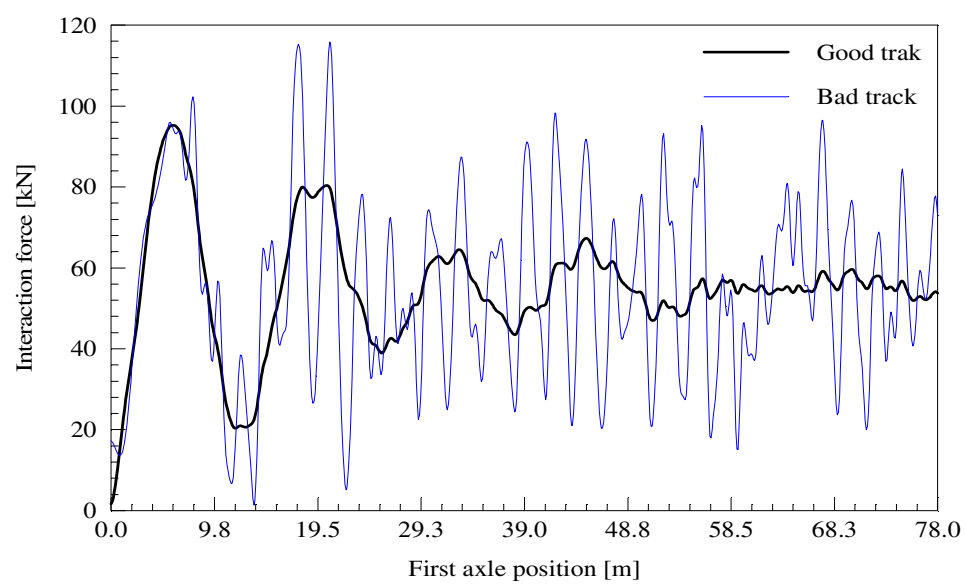

Fig. 10 Interaction force exerted by a right rear wheel of the vehicle, $v_{x}=100 \mathrm{~km} / \mathrm{h}$, loading case 3

\section{Conclusion}

In this paper the dynamic interaction between a moving vehicle (modeled as a nine degree of freedom dynamic system with tandem axles) and a bridge (modeled as a three-span orthotropic plate) was studied taking into account road surface irregularities. The modal method and Newmark's numerical integration were used to solve the coupled equations of bridge-vehicle motion. For this an iterative algorithm is proposed for solving the coupled equations of bridge-vehicle motion in a decoupled manner. Numerical simulations have been performed to study the variation of dynamic amplification factor on the bridge deck. Two major observations were made:

1. The distribution of the dynamic amplification factor on the bridge deck does not reflect a particular tendency, because high dynamic amplification factors can occur in places where the vertical displacement is weak.

2. In the case studied, the critical speed corresponding to the maximum dynamic amplification factor was about $133.2 \mathrm{~km} / \mathrm{h}$. This value varies according to the vehicle mass. 


\section{References}

Isabel, G.T.: Analyse par éléments finis de l'interaction dynamique entre les trains et les ponts ferroviaires. Mémoire de Maître ès en Art, Université Laval, Canada (2001)

Zhu, X.Q., Law, S.S.: Dynamic load on multi-lane bridge deck from moving vehicles. J. Sound Vib. 251, 697-716 (2002)

Yang, Y.B., Lin, C.W., Yau, J.D.: Extracting bridge frequencies from the dynamic response of a passing vehicle. J. Sound Vib. 272, 471-493 (2004)

Cai, C.S., Shi, X.M., Araujo, M., Chen, S.R.: Effect of approach span condition on vehicleinduced dynamic response of slab-on-girder road bridges. Eng. Struct. 29, 3210-3226 (2007)

Yin, X., Fang, Z., Cai, C.S., Deng, L.: Non-stationary random vibration ofbridges under vehicles with variable speed. Eng. Struct. 32, 2166-2174 (2010)

Rezaiguia, A.: Modélisation du comportement vibratoire et acoustique d'un pont de la chaussée lors du passage des véhicules. Thèse de doctorat, Université d'Annaba (2008)

Rezaiguia, A., Fisli, Y., Ellagoune, S., Laefer, D.F., Ouelaa, N.: Extension of semi- analytical approach to determine natural frequencies and mode shapes of a multi-span orthotropic bridge deck. Struct. Eng. and Mechanics 43, 71-87 (2012)

Rezaiguia, A., Laefer, D.F.: Semi-analytical determination of natural frequencies and mode shapes of multi-span bridge decks. J. Sound Vib. 328, 291-300 (2009)

Broquet, C.: Comportement des dalles de roulement des routes en béton sollicitées par le trafic routier. Thèse PhD, Ecole Politechnique Fidéral de Lausane (1999) 